\title{
Using Emergency Preparedness Strategies to Anticipate and Manage Emotional Responses and Distress during Pandemics
}

\author{
Annekathryn Goodman \\ Harvard Medical School, Massachusetts General Hospital, Boston, Massachusetts, USA \\ Email: agoodman@mgh.harvard.edu
}

How to cite this paper: Goodman, A. (2021). Using Emergency Preparedness Strategies to Anticipate and Manage Emotional Responses and Distress during Pandemics. Psychology, 12, 1198-1210.

https://doi.org/10.4236/psych.2021.128074

Received: May 9, 2021

Accepted: August 3, 2021

Published: August 6, 2021

Copyright $\odot 2021$ by author(s) and Scientific Research Publishing Inc. This work is licensed under the Creative Commons Attribution International License (CC BY 4.0).

http://creativecommons.org/licenses/by/4.0/ (c) (i) Open Access

\begin{abstract}
Objective: The COVID-19 pandemic has impacted every country in the world. The responses and outcomes to the pandemic have varied by country. The variations have been associated with the culture, governance, and resources of each country. Emergency preparedness follows the four phases of planning: mitigation, preparedness, response, and recovery. These phases are integral for a mature and functional emergency plan. Most plans do not factor in the emotional responses and mental health consequences of a pandemic. The purpose of this review is to develop a pandemic strategy that uses the four phases of emergency preparedness planning for training and addressing emotional responses and mental health outcomes of a catastrophic global infectious disease outbreak. Methods: The literature on COVID-19 emergency preparedness and mental health outcomes was reviewed. Results: Emotional reactions to public health measures vary depending on the clarity of communication and guidance by the leaders of each affected community. Isolation, anxiety, and depression are common responses to the impact of a pandemic. Risk factors for depression and mental health challenges include people who are essential frontline health and service workers, isolation, economic insecurity, and the duration of the quarantines. Conclusion: This commentary reviews the various nonmedical factors that contribute to stress and mental health challenges in a pandemic. Recommendations are given for planning and interventions in each of the 4 phases of emergency preparedness.
\end{abstract}

\section{Keywords}

COVID-19, Pandemic, Mental Health, Politics, Emergency Preparedness 


\section{Introduction}

There are many components to emergency preparedness and these components can be modified and applied to any disaster whether it is an earthquake or a pandemic. Despite a tremendous body of medical information about the spread of infectious diseases and in-depth historical analysis of previous epidemics and pandemics (Hays, 2005), human behavior and politics play a significant role in extending pandemics and increasing infections and deaths. While emergency preparedness focuses on disaster plans that include resource allocation, crisis standards of care, evacuation, and rescue, there has been little previous planning to factor in human behavior to determine how a population will respond to a pandemic leading to widespread illness and death. While acute and time-limited catastrophes can bring out communal and altruistic outreach among the affected population, prolonged crises such as pandemics can reveal a more irrational side to human responses (Gantt \& Gantt, 2012). Irrationality is an action or opinion defined as the lack of inclusion of rationality in thinking, acting, or decision-making (Vietta, 2013). This can occur due to emotional distress, inadequate use of reason or cognitive deficiency.

This paper reviews the role individual and collective behavior plays during a pandemic emergency. The basic four principles of emergency preparedness, mitigation, preparedness, response, and recovery can be harnessed to manage the complicated and potentially harmful human responses to catastrophic infectious disease.

The four phases of emergency management mitigation, preparedness, response, and recovery are integral for a mature and functional emergency plan. Each phase is unique in terms of the interventions, funding allocation, and goals but together a society has a robust plan to a disaster situation to reduce injury, loss of life, habitat, and financial devastation.

Mitigation is a sustained action to reduce or eliminate the risks of a disaster (FEMA, 2020). With good mitigation, disasters do not happen. Mitigation is about having the non-story. In some ways, mitigation requires the greatest foresight and understanding of the risk factors leading to a disaster.

Preparedness is the state of readiness to respond to a disaster. This phase has to do with having the imagination and experience to know what will be needed to protect people when disaster hits and plan for it. The preparedness planning cycle includes planning, organizing, equipping, evaluation, assessment, taking corrective action, then more planning, and preparation (FEMA, 2020). This cycle emphasizes the need to constantly re-evaluate the plan and to upgrade and change it based on new experience and after-action analysis from previous disasters.

Response is the actual actions and interventions of individuals, communities, and governments once a disaster has occurred. The response will use the plan put in place in the preparedness phase. Many aspects of response are universal, but response will also be unique to the situation.

Recovery is the phase of rebuilding, repairing, and healing. This phase re- 
quires financial support from insurance companies and the local and federal government. One aspect of recovery is the management of psychological loss loss of people, pets, and financial disaster from loss of jobs and homes. These interventions also involve interventions for post-traumatic stress disorder. There is also the need to plan interventions to reduce and prevent long-term mental health outcomes such a depression and suicide.

In general, emergency preparedness plans assume that a crisis will be finite and short-term (Santiago \& Smith, 2020). One of the challenges for emergency planning is how to maintain an emergency response and fund the resources needed to continue care when the crisis becomes long-term. This is an essential feature of the current COVID-19 pandemic and may be true for future pandemics to come.

The non-medical response to the COVID-19 has included politics, particular individual and collective human behavioral responses, and emotional consequences. It is worthwhile to examine the lessons learned from both other pandemics and the current COVID-19 pandemic to help develop an emergency response plan for future pandemics. The purpose of this review is to summarize the lessons learned from the COVID-19 and other significant pandemics and develop a pandemic strategy that uses the four phases of emergency preparedness planning for training for and addressing of emotional responses and mental health outcomes of a catastrophic global infectious disease outbreak.

\section{Methods}

This commentary used an Integrative Literature Review methodology to evaluate publications related to mental health, emotional responses and pandemics. Relevant publications were reviewed to analyze existing findings. Key words used to conduct the literature search were "COVID-19", "pandemic", "mental health", "politics", and "emergency preparedness". Abstracts were read to identify inclusion criteria, and selected publications were read entirely. Search engines and online libraries used were: Hollis (Harvard University Library Search Engine), BioMedical Central (BMC), National Center for Biotechnology Information (NCBI), PubMed (U.S. National Library of Medicine National Institute of Health). Inclusion criteria were: Qualitative and quantitative studies in the English language, published after 1990, which focused on questions of how emotional responses, and governance impacted responses to pandemics. Exclusion criteria were: Publications written before 1990. The time cut-off for review correlated with the Institute of Medicine publication identifying infectious diseases to be a significant and increasing danger for nations and the global community (Lederberg et al., 1992). A total of 31 publications were selected, read in full length, organized by politics, emotional responses, mental health outcomes, and recommendations for emergency preparedness planning.

\section{The Politics of Pandemics}

Societal responses are complicated by the politics of pandemics (Kapiriri \& Ross, 
2020). All government and community-based decisions about response to a pandemic has to factor in the political factions of society, the losses and benefits to different groups in society and the various special interests and agendas of different political platforms. Government officials will also factor in their own political survivability during a catastrophe. This may influence their decision-making and governance to the medical detriment of the population.

Table 1 lists the various decision sets that are influenced and affected by the politics of pandemics (Santiago \& Smith, 2000).

The political responses of governments that have hurt the public health response to pandemics and have led to increased numbers of infectious and deaths are listed in Table 2 (Santiago \& Smith, 2020). As an example, acceptability of mask wearing and mask wearing in general were associated with significantly lower mortality rates from COVID-19 (Leffler et al., 2020). Mask wearing and approval at the government level has been shown to directly affect mask use at the population level (Goldberg et al., 2020). A political analysis of plague literature identifies the political dangers stemming from the chaos of a pandemic with the rise of populist leaders that can lead to the loss of rights of minorities and vulnerable populations (Botting, 2021).

Table 1 . The politics of pandemics.

\section{Decision sets for governance during a pandemic}

Negotiating for adequate funding for public health preparedness

Coordinating a multifaceted response effort

Staffing essential healthcare workforce

Staffing essential work force for essential goods and services

Operation of critical supply chains

Balance of public health mandates with economic necessities

Funding research and technology

Providing adequate resources to mitigate disease transmission

Preparing for the possibility of multiple and synchronous public health disasters

Table 2. Political responses in a pandemic.

Political responses in a pandemic

Delay in Response

Lack of Coordination of response

Inaccurate and contradictory public health information

Inadequate testing capacity

Inadequate disease tracking

Poor medical infrastructure

Shortages of protective equipment for healthcare providers

Inadequate workplace protections for essential workers 
Over the past 30 years, there has been an increasing awareness of the threats posed by infectious diseases. In 1992, the United States Institute of Medicine's report, "Emerging Infections: Microbial Threats to Health in the United States", emphasized the dangers of infectious diseases as security threats to the United States (Lederberg et al., 1992). Risks are escalated because of globalization, which facilitates the spread of viruses and new pathogens due to deforestation and climate change (Lindahl et al., 2017). The most recent revision of the International Health Regulations (IHR) focuses on the development of public health capacities to detect new outbreaks in each country and the call to have governments not only accountable to their citizens and but also to the global community (de Bengy Puyvallée \& Kittelsen, 2019). The global challenge to effective worldwide collaboration to prevent or to develop intervention strategies during a pandemic is communication, trust between countries, and the particular relationships, treaties and tensions among affected countries. The outcomes from earlier pandemics can be instructive in planning for the next catastrophe. The 2014-2015 Ebola epidemic in West Africa identified several weaknesses in response. There was a delayed global response and the West African countries affected lacked the capacity to prevent transborder spread. The lessons learned illuminated the tension between national interest and collective action, neglect in strengthening low- and middle-income countries' infrastructure to manage outbreaks, and the significance of technology-based approaches as part of the pandemic response (de Bengy Puyvallée \& Kittelsen, 2019).

\section{The Nonmedical Impact of Public Health Measures in a Pandemic}

The response to the pandemic has identified disparities in healthcare, housing, and job security. The standard public health responses to infectious disease outbreaks include identification of victims, isolation and quarantine, contact tracing, and social distancing. These standard interventions affect different portions of the public differently. The impact breaks down across socioeconomic and educational lines in society. Historically, the poor have always been the most vulnerable to epidemics (Roberts, 2020). Table 3 lists various consequences for the impoverished of society.

Table 3. Consequences of public health response to pandemic.

Consequences of public health response to pandemic
Food insecurity
Lack of access to internet causing disparities and the digital divide
Education insecurity
Lack of access to transportation
Increased homelessness
Lack of access to healthcare


The hardships imposed can lead to protests and pushback by different segments of the population. Protests, riots, and civil disobedience have occurred in many previous epidemics and pandemics.

Table 4 lists examples of previous pandemics and the protests of communities to government public health measures (Hays, 2005). In general, isolation, quarantines, and seizure of infected properties led to varying degrees of revolt and riot among the affected populations throughout the centuries.

A recent systematic review of social consequences of mass quarantine examined fifteen recent articles (Chu et al., 2020). They found that the negative consequences of quarantine included psychological distress, communication inequalities, food insecurity, and gender-based violence. In another survey of 155 respondents in Turkey, female gender was noted to be a risk factor for anxiety and depression (Özdin \& Bayrak Özdin, 2020). These consequences are deeply personal and vary depending on the particular resources of each person and family. However, public protests have occurred over masking and quarantine measures during the COVID-19 pandemic as a consequence of politicizing the pandemic in the United States (Hutchinson, 2020).

Table 4. Examples of population protests in response to government interventions during epidemics or pandemics.

\begin{tabular}{|c|c|}
\hline Pandemic & Public Response (examples) \\
\hline Plague in Italian Cities 1630 & $\begin{array}{l}\text { Serious grievances and resentment of } \\
\text { quarantines }\end{array}$ \\
\hline Plague in Moscow 1771 & $\begin{array}{l}\text { Riots, looting, invasion of Kremlin, } \\
\text { killing of Archbishop }\end{array}$ \\
\hline First Cholera Pandemic 1817-1824 & $\begin{array}{l}\text { Manilla, Philippines: populace thought it was } \\
\text { a plot to poison the water; rioting }\end{array}$ \\
\hline & $\begin{array}{l}\text { St Petersburg, Russia: Riots, blamed police, } \\
\text { physicians, foreigners for epidemic }\end{array}$ \\
\hline Second Cholera Pandemic 1827-1835 & $\begin{array}{l}\text { Paris: Cholera was a hoax, and the elite } \\
\text { was poisoning people. Angry crowds } \\
\text { attacked doctors, hospitals }\end{array}$ \\
\hline Third Cholera Pandemic 1839-1856 & $\begin{array}{l}\text { Brazil: near chaos, government functions } \\
\text { stopped, patients were abandoned }\end{array}$ \\
\hline "Fevers" \& Great Famine in Ireland 1846-1850 & Complete disintegration of the social norms \\
\hline Fourth Cholera Pandemic 1863-1875 & $\begin{array}{l}\text { Egypt: Resentment and resistance against } \\
\text { government for trying to destroy property } \\
\text { of the sick }\end{array}$ \\
\hline Smallpox in Europe 1870-1875 & Britain: anti-vaccination movement \\
\hline Fifth Cholera Pandemic 1881-1896 & $\begin{array}{l}\text { In Naples, people defied bans on religious } \\
\text { processions } \\
\text { In Russia, mobs attacked medical personnel } \\
\text { and burned down cholera barrack } \\
\text { In India, widespread protests of closure of } \\
\text { Hindu pilgrimage }\end{array}$ \\
\hline Influenza Pandemic 1918-1919 & $\begin{array}{l}\text { USA: Skepticism about efficacy of mask } \\
\text { wearing, protests over closure of taverns, } \\
\text { schools, churches }\end{array}$ \\
\hline
\end{tabular}




\section{Review of Literature on Emotional Responses to Pandemic}

Gantt \& Gantt (2012) summarize the three models of human behavior in disaster and emergency scenarios: emergent norm theory, social attachment model, and self-categorization theory. All theories describe the prosocial foundation of human behavior and the importance of social bonds to cope with disasters and emergencies. Unlike natural disasters, one of the stressors leading to aberrations in human behavior during a pandemic is the social isolation that is demanded of people to prevent transmission of disease.

In a Brazilian survey of 16,440 respondents, social isolation as a mitigation factor varies by socioeconomic status, age, gender, and education (Bezerra et al., 2020). However isolation significantly impacts mental health. In a review of 83 articles, self-reported loneliness and social isolation were significantly associated with depression among children and adolescents (Loades et al., 2020). Similarly, a review of 41 articles including over 20 thousand interviews of individuals over age 60 years from countries in Asia, America and Europe confirmed the negative affects on mental and physical health of isolation (Sepúlveda-Loyola et al., 2020).

There has been significant stress and mental health issues with the COVID-19 pandemic. The insights from understanding the mental health outcomes can be used to prepare for future pandemics.

The survey by Petrocchi et al. (2021) looks at the experience in Italy during the quarantine. There were difficult mental and emotional responses including denial, depression, and anger. Intolerance to ambiguity was linked with distress. The lessons learned from this include the need to give clear communication about the ongoing pandemic and clear messages about how to stay safe.

Pedrossa et al. reviewed over 1340 articles on mental health disorders during the COVID pandemic. There is increased risk of suffering and mental health disorders. High risk groups for mental health stress include frontline healthcare workers, the elderly, children, college students, the LGBTQ community, the homeless, and those with economic vulnerability (Pedrossa et al., 2020). In a survey of 7143 undergraduate students in China, over one fifth of respondents experienced anxiety but only $0.9 \%$ had severe anxiety. Protective factors against anxiety included living in an urban area, family income stability, and living with parents (Cao et al, 2020). These findings support the need to prevent isolation during the quarantine.

The emotional stress of the pandemic has been linked to exacerbations in preexisting psychiatric conditions such as post-traumatic stress disorder, alcohol misuse, obsessive-compulsive disorders, panic, and paranoia (Guessoum et al., 2020; Heitzman, 2020; Hao et al., 2020). Four major vulnerabilities are identified among psychiatric patients. These include more frequent medical comorbidities, older age, cognitive and behavioral disorders, and psychological vulnerabilities that are exacerbated by stigmatization and socio-economic stressors (Chevance et al., 2020). There has also been an increase in addictive behaviors such as 
drugs, alcohol, tobacco, and Internet use (Sun et al., 2020).

Table 5 summarizes various types of emotional distress reported during the pandemic (Pedrossa et al., 2020). Stressors include economic instability, domestic violence, sleep disturbances, increased news monitoring, changed in routines such as exercise and eating. The impact of quarantine includes feelings of anxiety, anger, stress, PTSD, social isolation, loneliness, and stigmatization (Röhr et al., 2020). Risk factors include the duration of quarantine and income losses. Healthcare workers were particularly vulnerable.

In a study of 613 subjects, $40 \%$ of subjected experienced anxiety and $41.3 \%$ had depression (Pérez-Cano et al., 2020). Another literature review of 28 articles on mental health during the COVID pandemic identified high levels of depression and anxiety (Rajkumar, 2020). In addition, vicarious traumatization among non-frontline nurses and the general public was higher than for frontline workers.

\section{Emergency Preparedness, Planning and Response to the Threat of Pandemics}

Emergency preparedness requires an understanding of human behavior and a working knowledge of effective interventions for anxiety, stress, depression, and other mental health condition. Therapeutic interventions are listed in Table 6.

Table 5. Types of emotional distress in a pandemic.

\begin{tabular}{ll}
\hline TYPES OF EMOTIONAL DISTRESS \\
\hline Feelings of functional impairment \\
Boredom \\
Stigma \\
Worry \\
Phobia \\
Frustration \\
Anger \\
Fear \\
Uncertainty
\end{tabular}

Table 6. Therapeutic interventions.

Therapeutic interventions for emotional and mental distress

Development of teams of specialists qualified in emotional distress

Training community healthcare workers in basic aspects of mental health

Online surveys

Online material for mental health education

Online counseling

Online self-help services

Tele-psychiatry services

Availability of services to low-income people 
In addition, basic interventions to improve well-being such as exercise programs have clear correlations with improved mental health (Morrey et al., 2020; Zhang et al., 2020; Chevance et al., 2020; Violant-Holz et al., 2020). Gantt suggests planning and preparation through identifying emergency systems for clear communication. Communication must be specific, clear, and contain detailed protocols to follow. Setting up these protocols in advance and making them available and familiar to the general public may alleviate some of the stress of uncertainty. A second component of preparedness is training. Desktop strategic exercises with pandemic scenarios can be used in schools, work places, and other places of gathering such as places of worship. If large groups of the community are educated as to how to respond to infectious diseases such as by masking and social distancing, these measures will feel less bizarre and culturally dissonant should they become necessary.

Kaslow et al. (2020) uses a behavioral pandemic response strategy: preplanning, response readiness, response mobilization, intervention, continuation, and amelioration. These strategies can become a road map to follow for future planning and intervention for emotional and behavioral challenges that occur from stress, deprivation, and loss of societal stimulation that occurs in a pandemic. A six-phase response strategy is described for the six phases of pandemic progression: Investigation, recognition, initiation, acceleration of epidemic curve, deceleration of epidemic curve, preparation for new outbreaks. During each of these phases, communication, education, use of cultural and religious support systems can be used to reduce stress. Behavioral specialists, social workers, cultural and religious leaders of communities must be included in emergency preparedness planning.

Strategies for preventing and alleviating mental health stresses must include community planning. Table 7 summarizes interventions to increase individual and community resilience (Landesman \& Burke, 2017).

Table 8 summarizes the use of the four phases of emergency management mitigation, preparedness, response, and recovery in preparing for and intervening to prevent and respond to the emotional, behavioral, and mental health stresses of a pandemic.

Table 7. Emergency preparedness planning for mental health resilience.

\begin{tabular}{l}
\hline INTERVENTIONS \\
\hline Support the community in all sectors: government, nonprofits, business \\
Develop credible and competent leadership \\
Establish realistic expectations \\
Preparatory training in stress management and coping skills \\
Redundancy to support systems, preparedness plans and community capacity \\
Effective communication with accurate information \\
Develop a sense of connectedness \\
Develop social support structures
\end{tabular}


Table 8. Emergency planning for emotional, behavorial, and mental health stress of pandemics.

\begin{tabular}{|c|c|}
\hline $\begin{array}{c}\text { Four phases of } \\
\text { emergency management }\end{array}$ & Interventions \\
\hline Mitigation & $\begin{array}{l}\text { - Government policy development of allocation of funds for } \\
\text { - } \quad \text { Devergency planning and development } \\
\text { surveillance program } \\
\text { - International cooperation among national public health and } \\
\text { infectious disease centers of each country } \\
\text { - Development of local community and spiritual resources } \\
\text { - Widespread vaccination programs }\end{array}$ \\
\hline Preparedness & $\begin{array}{l}\text { - Educational programs to teach populations about infectious } \\
\text { diseases, prevention, transmission, and response } \\
\text { - Education about personal protective equipment } \\
\text { - Training of teachers, healthcare professionals, spiritual leaders } \\
\text { in psychological first aid } \\
\text { - A national mechanism for emergency production of personal } \\
\text { protective equipment }\end{array}$ \\
\hline Response & $\begin{array}{l}\text { - Clear and consistent communication about unfolding } \\
\text { - } \text { infectious disease crisis } \\
\text { - telephone, and community based therapy } \\
\text { - Accessible online programs of exercise classes } \\
\text { - Enactment of peer and community support systems } \\
\text { - Utilization of shelters with social distancing } \\
\text { - } \quad \text { Food banks and distribution of food to quarantined populations }\end{array}$ \\
\hline Recovery & $\begin{array}{l}\text { - Creation of a space for narrative and art to commemorate } \\
\text { those who died and the experiences of survivors } \\
\text { - Mental health resources }\end{array}$ \\
\hline
\end{tabular}

\section{Conclusion}

Pandemic preparedness and response are not just about medical and public health planning. Global security and political tensions are threatened and increased when a global pandemic requires cooperation, communication, and collaboration among vastly different regions with different resources and infrastructures (de Bengy Puyvallée \& Kittelsen, 2019). The handling of a pandemic is related to the governance of each affected country. Trust in leadership is essential for a population's buy-in of public health measures (Roberts, 2020).

It is crucial to understand the tremendous mental health consequences of both the illness and losses that occur in a pandemic and the significant disruption of all aspects of life including education, the home environment, work, and loss of normal social and community supports. It is essential that emergency preparedness planners include mental health interventions and work with community leaders to provide safe spaces for people during this stressful time.

\section{Conflicts of Interest}

The author declares no conflicts of interest regarding the publication of this paper. 


\section{References}

Bezerra, A. C. V., Silva, C. E. M. D., Soares, F. R. G., \& Silva, J. A. M. D. (2020). Factors Associated with People's Behavior in Social Isolation during the COVID-19 Pandemic. Ciencia Saude Coletiva, 25, 2411-2421. https://doi.org/10.1590/1413-81232020256.1.10792020

Botting, E. H. (2021). Predicting the Patriarchal Politics of Pandemics from Mary Shelley to COVID-19. Frontiers in Sociology, 6, Article ID: 624909. https://doi.org/10.3389/fsoc.2021.624909

Cao, W., Fang, Z., Hou, G., Han, M., Xu, X., Dong, J., \& Zheng, J. (2020). The Psychological Impact of the COVID-19 Epidemic on College Students in China. Psychiatry Research, 287, Article ID: 112934. https://doi.org/10.1016/j.psychres.2020.112934

Chevance, A., Gourion, D., Hoertel, N., Llorca, P. M., Thomas, P., Bocher, R., Moro, M. R., Laprévote, V., Benyamina, A., Fossati, P., Masson, M., Leaune, E., Leboyer, M., \& Gaillard, R. (2020). Ensuring Mental Health Care during the SARS-CoV-2 Epidemic in France: A Narrative Review. L'Encephale, 46, 193-201.

https://doi.org/10.1016/j.encep.2020.04.005

Chu, I. Y.-H., Alam, P., Larson, H. J., \& Lin, L. (2020). Social Consequences of Mass Quarantine during Epidemics: A Systematic Review with Implications for the COVID-19 Response. Journal of Travel Medicine, 27. https://doi.org/10.1093/jtm/taaa192

de Bengy Puyvallée, A., \& Kittelsen, S. (2019) "Disease Knows No Borders": Pandemics and the Politics of Global Health Security. In K. Bjørkdahl, \& B. Carlsen (Eds.), Pandemics, Publics, and Politics. Palgrave Pivot.

https://doi.org/10.1007/978-981-13-2802-2 5

FEMA (2020). Hazard Mitigation Planning.

https://www.fema.gov/emergency-managers/risk/hazard-mitigation-planning

Gantt, P., \& Gantt, R. (2012). Disaster Psychology: Dispelling the Myths of Panic. Emergency Planning.

https://aeasseincludes.assp.org/professionalsafety/pastissues/057/08/042 049_F1Gan 0 812.pdf

Goldberg, M. H., Gustafson, A., Maibach, E. W., Ballew, M. T., Bergquist P., Kotcher, J. E., Marlon, J. R., Rosenthal, S. A., \& Leiserowitz, A. (2020). Mask-Wearing Increased after a Government Recommendation: A Natural Experiment in the U.S. during the COVID-19 Pandemic. Frontiers in Communication, 5, 44 p.

https://www.frontiersin.org/article/10.3389/fcomm.2020.00044

https://doi.org/10.3389/fcomm.2020.00044

Guessoum, S. B., Lachal, J., Radjack, R., Carretier, E., Minassian, S., Benoit, L., \& Moro, M. R. (2020). Adolescent Psychiatric Disorders during the COVID-19 Pandemic and Lockdown. Psychiatry Research, 291, Article ID: 113264. https://doi.org/10.1016/j.psychres.2020.113264

Hao, F., Tan, W., Jiang, L., Zhang, L., Zhao, X., Zou, Y., Hu, Y., Luo, X., Jiang, X., McIntyre, R. S., Tran, B., Sun, J., Zhang, Z., Ho, R., Ho, C., \& Tam, W. (2020). Do Psychiatric Patients Experience More Psychiatric Symptoms during COVID-19 Pandemic and Lockdown? A Case-Control Study with Service and Research Implications for Immunopsychiatry. Brain Behavior and Immunity, 87, 100-106.

Hays, J. N. (2005). Epidemics and Pandemics: Their Impacts on Human History. ABC-CLIO.

Heitzman, J. (2020). Impact of COVID-19 Pandemic on Mental Health. Psychiatria Polska, 54, 187-198. https://doi.org/10.12740/PP/120373 
Hutchinson, B. (2020). Protests against Coronavirus 'Stay-at-Home' Orders Spread across the Country: President Appears to Be Supporting the Protests against His Own Guidelines. ABC News.

https://abcnews.go.com/US/protests-coronavirus-stay-home-orders-spread-country/st ory?id=70242988

Kapiriri, L., \& Ross, A. (2020). The Politics of Disease Epidemics: A Comparative Analysis of the SARS, Zika, and Ebola outbreaks. Global Social Welfare, 7, 33-45.

https://doi.org/10.1007/s40609-018-0123-y

Kaslow, N. J., Friis-Healy, E. A., Cattie, J. E., Cook, S. C., Crowell, A. L., Cullum, K. A., Del Rio, C., Marshall-Lee, E. D., LoPilato, A. M., VanderBroek-Stice, L., Ward, M. C., White, D. T., \& Farber, E. W. (2020). Flattening the Emotional Distress Curve: A Behavioral Health Pandemic Response Strategy for COVID-19. American Psychologist, 75, 875-886. https://doi.org/10.1037/amp0000694

Landesman, L. Y., \& Burke, R. V. (2017). Public Health Management of Disasters. The Practice Guide Fourth Edition Alpha Press.

https://doi.org/10.2105/9780875532806

Lederberg, J., Shope, R. E., \& Oaks, S. C. (1992). Emerging Infections: Microbial Threat to Health in the United States. Institute of Medicine (US) Committee on Emerging Microbial Threats to Health. National Academies Press (US).

Leffler, C. T., Ing, E., Lykins, J. D., Hogan, M. C., McKeown, C. A., \& Grzybowski, A. (2020). Association of Country-Wide Coronavirus Mortality with Demographics, Testing, Lockdowns, and Public Wearing of Masks. The American Journal of Tropical Medicine and Hygiene, 103, 2400-2411.

https://www.ajtmh.org/view/journals/tpmd/103/6/article-p2400.xml

https://doi.org/10.4269/ajtmh.20-1015

Lindahl, J., Bett, B., Robinson, T., \& Grace, D. (2017). Rift Valley Fever and the Changing Environment: A case study in East Africa. In M. Bouzid (Ed.), Examining the Role of Environmental Change on Emerging Infectious Diseases and Pandemics (pp. 178-204). The International Livestock Research Institute (ILRI). https://doi.org/10.4018/978-1-5225-0553-2.ch008

Loades, M. E., Chatburn, E., Higson-Sweeney, N., Reynolds, S., Shafran, R., Brigden, A., Linney, C., McManus, M. N., Borwick, C., \& Crawley, E. (2020). Rapid Systematic Review: The Impact of Social Isolation and Loneliness on the Mental Health of Children and Adolescents in the Context of COVID-19. Journal of American Academy of Child and Adolescent Psychiatry, 59, 1218-1239. https://doi.org/10.1016/j.jaac.2020.05.009

Morrey, L. B., Roberts, W. O., \& Wichser, L. (2020). Exercise-Related Mental Health Problems and Solutions during the COVID-19 Pandemic. Current Sports Medicine Reports, 19, 194-195. https://doi.org/10.1249/JSR.0000000000000725

Özdin, S., \& Bayrak Özdin, Ş. (2020). Levels and Predictors of Anxiety, Depression and Health Anxiety during COVID-19 Pandemic in Turkish Society: The Importance of Gender. International Journal of Social Psychiatry, 66, 504-511. https://doi.org/10.1177/0020764020927051

Pedrossa, A. L., Bitencourt. L., Fróes. A. C. F., Cazumbá. M. L. B., Campos. R. G. B., de Brito, S. B. C. S., Simões, E., \& Silva, A. C. (2020). Emotional, Behavioral, and Psychological Impact of the COVID-19 Pandemic. Frontiers Psychology, 11, Article ID: 566212. https://doi.org/10.3389/fpsyg.2020.566212

Pérez-Cano, H. J., Moreno-Murguía, M. B., Morales-López, O., Crow-Buchanan, O., English, J. A., Lozano-Alcázar, J., \& Somilleda-Ventura, S. A. (2020). Anxiety, Depression, and Stress in Response to the Coronavirus Disease-19 Pandemic. Cirugia y Cirujanos, 
88, 562-568. https://doi.org/10.24875/CIRU.20000561

Petrocchi, S., Iannello, P., Ongaro, G., Antonietti, A., \& Pravettoni, G. (2021). The Interplay between Risk and Protective Factors during the Initial Height of the COVID-19 Crisis in Italy: The Role of Risk Aversion and Intolerance of Ambiguity on Distress. Current Psychology, 19, 1-12. https://doi.org/10.1007/s12144-021-01601-1

Rajkumar, R. P. (2020). COVID-19 and Mental Health: A Review of the Existing Literature. Asian Journal of Psychiatry, 52, Article ID: 102066.

https://doi.org/10.1016/j.ajp.2020.102066

Roberts, A. (2020). Pandemics and Politics. Survival, 62, 7-40. https://doi.org/10.1080/00396338.2020.1819641

Röhr, S., Müller, F., Jung, F., Apfelbacher, C., Seidler, A., \& Riedel-Heller, S. G. (2020). Psychosocial Impact of Quarantine Measures during Serious Coronavirus Outbreaks: A Rapid Review. Psychiatrische Praxis, 47, 179-189. https://doi.org/10.1055/a-1159-5562

Santiago, A. M., \& Smith, R.J. (2020). Community Practice, Social Action, and the Politics of Pandemics. Journal of Community Practice, 28, 89-99. https://doi.org/10.1080/10705422.2020.1763744

Sepúlveda-Loyola, W., Rodríguez-Sánchez, I., Pérez-Rodríguez, P., Ganz, F., Torralba, R., Oliveira, D.V., \& Rodríguez-Mañas, L. (2020). Impact of Social Isolation Due to COVID-19 on Health in Older People: Mental and Physical Effects and Recommendations. Journal of Nutrition Health \& Aging, 24, 938-947.

https://doi.org/10.1007/s12603-020-1500-7

Sun, Y., Li, Y., Bao, Y., Meng, S., Sun, Y., Schumann, G., Kosten, T., Strang, J., Lu, L., \& Shi, J. (2020). Brief Report: Increased Addictive Internet and Substance Use Behavior during the COVID-19 Pandemic in China. The American Journal on Addictions, 29, 268-270. https://doi.org/10.1111/ajad.13066

Vietta, S. (2013). A Theory of Global Civilization: Rationality and the Irrational as the Driving Forces of History. Kindle Ebooks.

Violant-Holz, V., Gallego-Jiménez, M. G., González-González, C. S., Muñoz-Violant, S., Rodríguez, M. J., Sansano-Nadal, O., \& Guerra-Balic, M. (2020). Psychological Health and Physical Activity Levels during the COVID-19 Pandemic: A Systematic Review. International Journal of Environmental Research and Public Health, 17, 9419. https://doi.org/10.3390/ijerph17249419

Zhang, Y., Zhang, H., Ma, X., \& Di, Q. (2020). Mental Health Problems during the COVID-19 Pandemics and the Mitigation Effects of Exercise: A Longitudinal Study of College Students in China. International Journal of Environmental Research and Public Health, 17, 3722. https://doi.org/10.3390/ijerph17103722 